
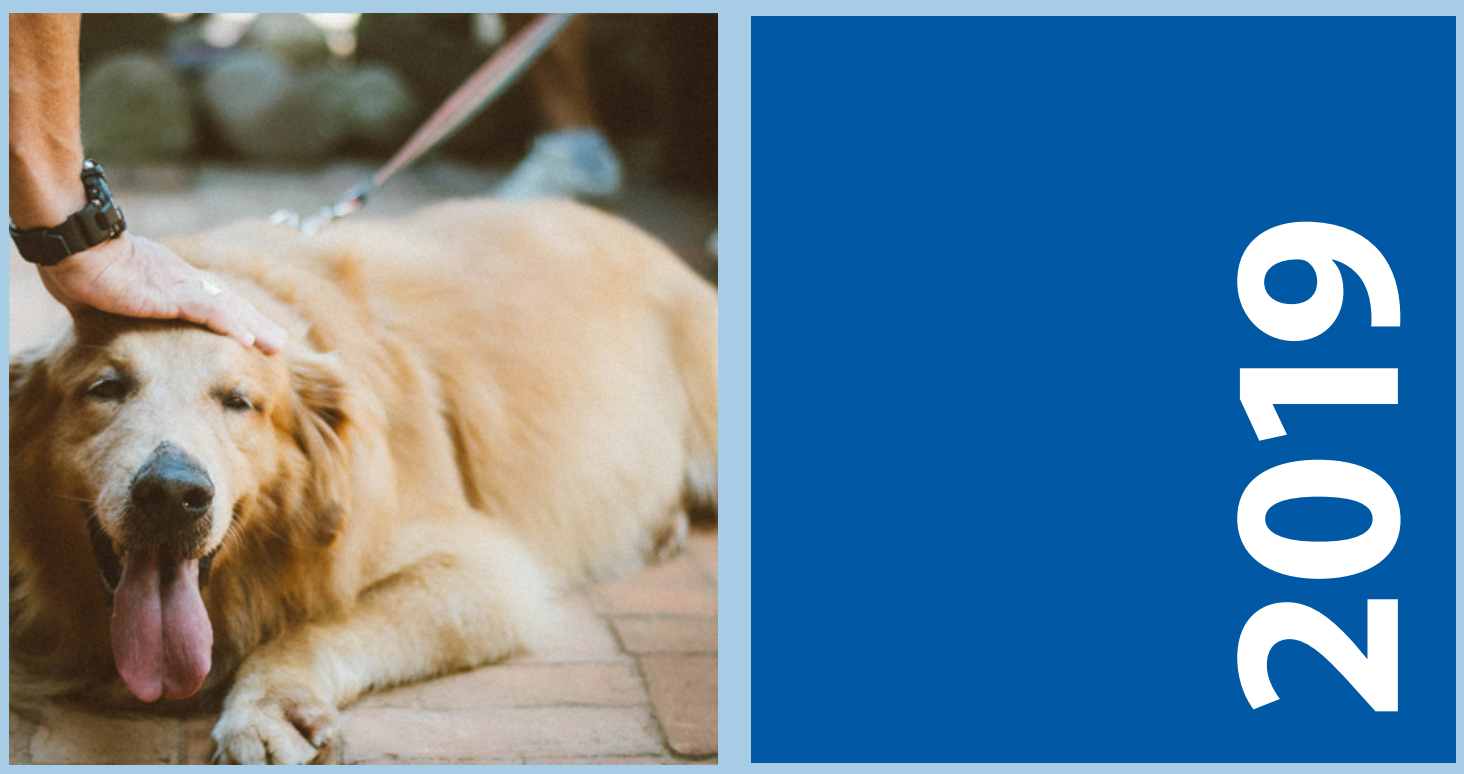

Associations of pet ownership with health and wellbeing in community-dwelling adults aged 50 years and over in Ireland

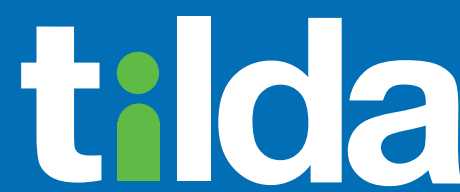

Staidéar Fadaimseartha na hÉireann um Dhul in Aois

The Irish Longitudinal Study on Ageing 


\section{Associations of pet ownership with health and wellbeing in community-dwelling adults aged 50 years and over in Ireland}

Orna Donoghue, Christine McGarrigle, Rose Anne Kenny

The Irish Longitudinal Study on Ageing

On behalf of the TILDA team

August 2019 
Copyright (C) The Irish Longitudinal Study on Ageing 2019

The Irish Longitudinal Study on Ageing

Lincoln Place

Trinity College Dublin

Dublin 2

Tel: +35318962509

Email: tilda@tcd.ie

Website: www.tilda.ie

ISBN: 978-1-907894-23-7

https://www.doi.org/10.38018/TildaRe.2019-01 


\section{Key Findings}

- Almost half (45\%) of adults aged 50 years and over in Ireland own a pet with dogs being most common (38\%) followed by cats $(21 \%)$.

- Dog ownership decreases with increasing age from $51 \%$ of adults aged $50-64$ years to $25 \%$ of those aged 75 and over.

- Almost two-fifths (38\%) of dog owners walk their dog every day. Regardless of age, four of every five women report walking their dog at least three times per week, however only $67 \%$ of men aged $50-64$ years do so compared to $84 \%$ of men aged 65 74 years which may be due to work commitments.

- Dog owners are more likely to report high levels of physical activity (33\%) compared to non-pet owners (24\%) and those who own other pets (22\%); dog owners who report regularly walking their dogs also report higher physical activity levels.

- Three-fifths (58\%) of dog owners report achieving the target 150 minutes per week of walking, compared to $51 \%$ of those with no pets and $45 \%$ of those with other pets.

- While rural dwellers are twice as likely to have a dog compared to those in Dublin $(49 \%$ versus $26 \%$ ), rural dog owners are less likely to achieve the target minutes walking compared to those in Dublin or other towns/cities (53\% versus $64-67 \%$ ).

- Female dog owners are more likely to report being current smokers, however those who walk their dogs regularly have lower body mass index compared to non-regular dog walkers.

- Dog owners have higher hand grip strength compared to adults who do not own any pets $(28.7$ versus $26.6 \mathrm{~kg}$ ). Grip strength is a marker of muscle strength and frailty.

- Dog owners who walk their dog at least three times a week are more likely to report active and social leisure activities in the past month (92\% versus $86 \%)$ and close social relationships (44\% versus $27 \%$ ) than dog owners who walk their dog less frequently. The higher close social relationships among regular dog walkers is particularly evident for men.

- The reason for owning a pet is an important factor in explaining different mental health and wellbeing outcomes associated with dog ownership. While pet owners who report having a pet because they love animals have a higher sense of purpose in life, those who have a pet to keep busy or to have something to take care of, have lower wellbeing scores.

- It is important to consider the potential benefits of exposure to and interactions with pets and consequently, how to facilitate older adults to keep pets for as long as they wish to do so. 


\section{Acknowledgements}

We would like to acknowledge the vision and commitment of our study funders, The Department of Health with support from the Health Research Board; The Atlantic Philanthropies and Irish Life plc. We would like to state that any views expressed in this report are not necessarily those of the Department of Health or of the Minister for Health. We would also like to thank the TILDA participants without whom this research would not be possible. 


\section{Contents}

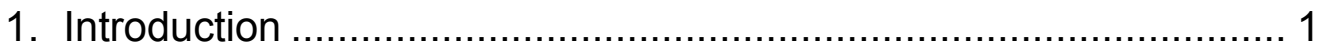

2. Characteristics of adults aged 50 years and over in Ireland .......... 4

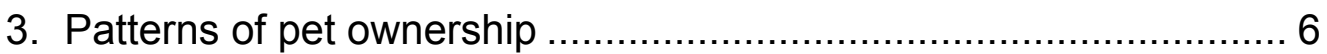

4. Dog ownership and physical, behavioural and functional

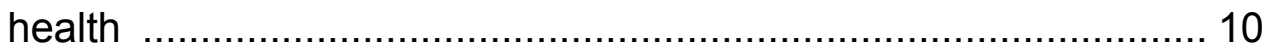

5. Dog ownership and social participation, mental health and wellbeing 18

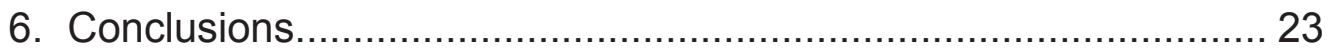

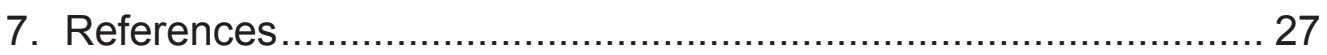




\section{Introduction}

Pet ownership is extremely common with $39-51.5 \%$ of community-dwelling older adults reporting having a pet $(1,2)$, although this does decrease with increasing age $(3,4)$. It is commonly accepted that having a pet is associated with better physical and mental health and wellbeing, however the scientific evidence to support this is lacking with many studies presenting conflicting results. For example, some research has reported positive physical and mental health effects of dog or pet ownership (4-6); some found little difference between pet owners and non-pet owners (7) and some found poorer mental and physical health and higher use of pain relief medication in pet owners (8). Many of these papers are cross-sectional and rely on self-reported measures of health and function.

Recent review papers have shown that dog owners are more physically active and walk more than non-dog owners (9) with similar findings in dog owners who walk their dogs compared to those who do not (10). The mechanisms through which pet ownership could explain better health are not clear although dog walking has been proposed as a potential mechanism through which dog ownership could lead to better physical health (11). Physical activity can also promote social interactions with others which can lead to improved psychosocial wellbeing. In support of this, Curl and colleagues (11) reported that dog ownership alone was not associated with better physical or behavioural health, however walking a dog was associated with fewer chronic conditions, lower body mass index (BMI), fewer limitations in activities of daily living, fewer doctor visits and more frequent moderate and vigorous exercise.

Currently, the direction of the proposed relationship is also not clear - are dog owners healthier because they have a dog or are healthy individuals more likely to get a dog as this fits within their healthier lifestyles? It has also been argued that good physical health may be required to own a pet (8). Furthermore, studies suggest that dog owners who report a stronger attachment to their dog walk with them more frequently and for longer durations (11), suggesting that the reason for having a pet may also be important.

A two-fold increase in the Irish population aged 65 years and over has been projected for 2041 (12) which will lead to an increase in the number of older adults. With increasing age, 
there is typically an increase in the number of chronic conditions, age-related declines in function and decreasing levels of physical activity. It is important to understand the extent to which pets, and particularly dogs, are related to better physical, behavioural and mental health in older adults as this may represent a mechanism through which improved health can be facilitated.

In this report, we examine pet ownership in community-dwelling adults aged 50 years and older in Ireland. We examine the associations between pet ownership, specifically dog ownership and indicators of physical health, social participation and mental health and wellbeing. We also examine how frequency of dog walking affects all outcomes in dog owners. Finally, mental health and social wellbeing outcomes are examined in relation to the reasons for having a pet.

\subsection{Data and Methods}

This report uses data collected during the fifth wave of The Irish Longitudinal Study on Ageing (TILDA), a prospective study of 8,172 community-dwelling adults aged 50 years and older in Ireland. At Wave 5, 5,202 participants took part in a comprehensive Computer Assisted Personal Interview (CAPI) conducted by social interviewers who visited the respondents in their own homes (13). This included detailed questions on sociodemographics, living circumstances, income and wealth, physical, mental and behavioural health, health care utilization and social participation. Participants were also asked to fill out a self-completion questionnaire (SCQ) which included questions about pet ownership and more sensitive questions about relationships and experiences of growing older. The response rate for the SCQ was $84.5 \%(n=4,396)$. As the focus of this report is pet ownership, only those participants aged 50 years and over who completed the relevant pet questions in the SCQ were included in this analysis $(n=4,192)$. Data collection took place between January and December 2018.

\subsection{Statistical Methods and Weighting}

In this report, the percentage of respondents classified into different groups or average scores (means) on the different outcome scales are presented. Most estimates are provided with a $95 \%$ confidence interval. This can be interpreted as a $95 \%$ chance that the sampled confidence interval includes the true population value. All estimates are weighted to account for age, sex, educational attainment and urban/rural residence in the 2011

Census, and to reflect the probability that participants returned a completed SCQ, ensuring that these estimates are representative of the whole population aged 50 years and over in Ireland. 


\subsection{Structure of the Report}

The report is organised as follows. Section 1 provides a background to the topic describing the current research on pet ownership, and specifically dog ownership, in the context of an ageing population. Section 2 describes the characteristics of the community-dwelling adults aged 50 years and over resident in Ireland who were eligible for this analysis. Section 3 describes the prevalence of pet ownership, stratified by age group, sex, marital status and local area. Section 4 explores the associations between dog ownership and regular dog walking with indicators of physical, behavioural and functional health. Section 5 explores the associations with social participation, mental health and wellbeing with further analysis based on the reasons for having a pet. Finally, Section 6 summarises the findings, highlights the relevance to successful ageing and suggests areas in which these findings could inform policy and practice. 


\section{2 Characteristics of adults aged $\mathbf{5 0}$ years and over in Ireland}

Basic demographic indicators (age, sex, educational status) were obtained during the CAPI. Educational status was defined as primary, secondary or tertiary corresponding to $\leq 8,9-13$ and $>13$ years of education respectively. Marital status (married, single, separated/divorced, widowed) and local area (Dublin city or county, another town/city, rural area) were also obtained. Participants reported if a doctor had ever diagnosed them with any of the following conditions: heart attack, heart failure, angina, stroke, transient ischemic attack, heart murmur, diabetes, chronic lung disease, asthma, arthritis, osteoporosis and cancer. The number of health conditions reported was categorised as 0 , 1,2 and 3 or more conditions. Participants also self-rated their health relative to others of similar age as Excellent, Very Good, Good, Fair or Poor.

Descriptive characteristics of the 4,192 participants aged 50 years and over who provided information about pet ownership are shown in Table 1. One third (34.9\%) were aged between 50 and 64 years, while one in four $(25.4 \%)$ were 75 years or over. $56.5 \%$ of the population aged 50 and over were women and the majority were married (68.3\%). Over one in four (26.8\%) lived in Dublin city or county while two-fifths lived in rural areas (42.1\%). Three-quarters reported none or only one condition while $17.1 \%$ and $6.9 \%$ reported 2 conditions and 3 or more conditions respectively. $83.1 \%$ self-rated their health as good, very good or excellent.

There were some gender differences, most notably that women were more likely to be widowed $(22.4 \%$ versus $8.8 \%)$ and to have at least 2 health conditions compared to men (30.2\% versus $17.4 \%)$. There were also age-related differences, for example, the oldest group aged 75 years and older were less likely to have tertiary education (17.9\% versus $33.2 \%$ ) and more likely to be widowed (36.3\% versus $4.7 \%$ ) in comparison to those aged 50-64 years. The oldest group were also in poorer health than the youngest group; more likely to have two or more health conditions (34.4\% versus $15.1 \%)$ and to rate their health as fair or poor $(20.4 \%$ versus $14.0 \%)$. 
Table 1. Descriptive characteristics of adults aged 50 years and over in Ireland $(n=4,192)$

\begin{tabular}{|c|c|c|c|}
\hline & Men & Women & Total \\
\hline & $N(\%)$ & $N(\%)$ & $N(\%)$ \\
\hline \multicolumn{4}{|l|}{ Age } \\
\hline $50-64$ years & $550(35.2)$ & $850(34.6)$ & $1,400(34.9)$ \\
\hline $65-74$ years & $742(40.7)$ & $945(38.8)$ & $1,687(39.7)$ \\
\hline$\geq 75$ years & $532(24.1)$ & $573(26.6)$ & $1,105(25.4)$ \\
\hline \multicolumn{4}{|l|}{ Education } \\
\hline Primary level & $412(31.9)$ & $414(28.1)$ & $826(29.9)$ \\
\hline Secondary level & $737(41.4)$ & $917(48.6)$ & $1,654(45.1)$ \\
\hline Tertiary level & $675(26.7)$ & $1,037(23.3)$ & $1,712(25.0)$ \\
\hline \multicolumn{4}{|l|}{ Marital status } \\
\hline Married & $1,395(74.9)$ & $1,556(62.1)$ & $2,951(68.3)$ \\
\hline Single & $164(10.7)$ & $164(7.1)$ & $328(8.8)$ \\
\hline Divorced/Separated & $97(5.7)$ & $183(8.4)$ & $280(7.1)$ \\
\hline Widowed & $168(8.8)$ & $465(22.4)$ & $633(15.8)$ \\
\hline \multicolumn{4}{|l|}{ Local area } \\
\hline Dublin (city or county) & $471(26.0)$ & $583(27.4)$ & $1,054(26.8)$ \\
\hline Other town/city & $527(31.2)$ & $671(31.0)$ & $1,198(31.1)$ \\
\hline Rural area & $826(42.8)$ & $1,114(41.5)$ & $1,940(42.1)$ \\
\hline \multicolumn{4}{|l|}{ Health conditions } \\
\hline 0 conditions & $868(46.6)$ & $856(33.8)$ & $1,724(40.0)$ \\
\hline 1 condition & $662(36.0)$ & $853(36.0)$ & $1,515(36.0)$ \\
\hline 2 conditions & $210(12.3)$ & $481(21.6)$ & $691(17.1)$ \\
\hline$\geq 3$ conditions & $84(5.1)$ & $178(8.6)$ & $262(6.9)$ \\
\hline \multicolumn{4}{|l|}{ Self-rated health } \\
\hline Excellent & $228(11.7)$ & $352(12.2)$ & $580(12.0)$ \\
\hline Very good & $668(35.9)$ & $871(35.3)$ & $1,539(35.6)$ \\
\hline Good & $644(34.9)$ & $814(36.0)$ & $1,458(35.5)$ \\
\hline Fair & $249(15.4)$ & $278(13.8)$ & $527(14.5)$ \\
\hline Poor & $35(2.1)$ & $53(2.7)$ & $88(2.4)$ \\
\hline
\end{tabular}




\section{Patterns of pet ownership}

\subsection{Pet ownership by demographic factors}

In the SCQ, participants were asked to indicate if they currently own any pets from a list provided (dog, cat, small mammal, birds, fish) with an option to provide details about any other pet they have. Almost half (45.3\%) of adults aged 50 years and over report owning a pet. Dogs are the most commonly owned pet $(38.0 \%)$ followed by cats $(21.2 \%)$, fish $(5.2 \%)$, birds $(3.7 \%)$, small mammals $(1.7 \%)$ and other animals $(2.0 \%)$.

There are no differences between men and women in terms of pet ownership, however there are significant differences between younger and older adults (Figure 1). Adults aged 50-64 years are more likely to have a pet (56.8\%) compared to those aged $65-74$ years $(43.2 \%)$ and 75 years and over (32.9\%). This age effect is particularly evident for dog owners where $50.5 \%$ of $50-64$ year olds have a dog compared to $24.9 \%$ of those aged 75 and over.

Figure 1. Pet ownership, by age group

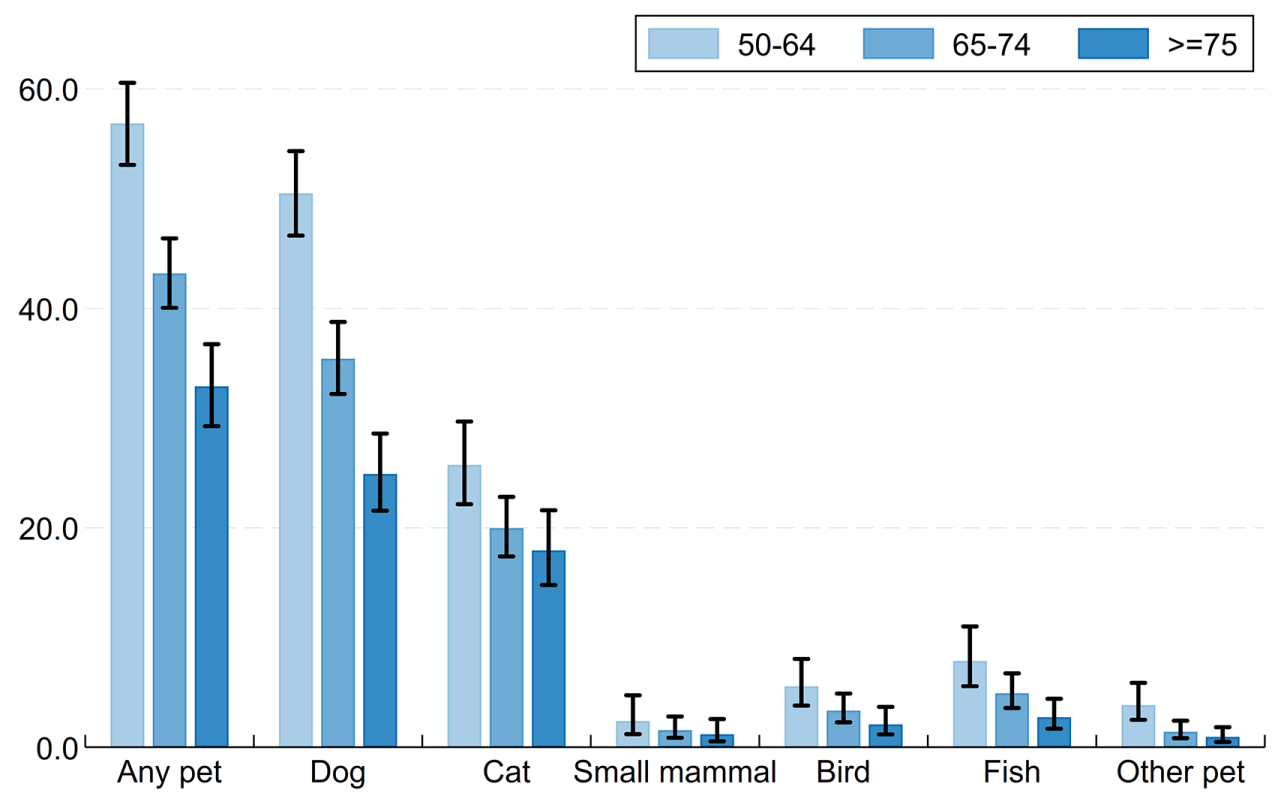


Pet ownership varies with marital status with married individuals more likely to report having a current pet, particularly dogs compared to those who are widowed (Figure 2).

Figure 2. Pet ownership, by marital status

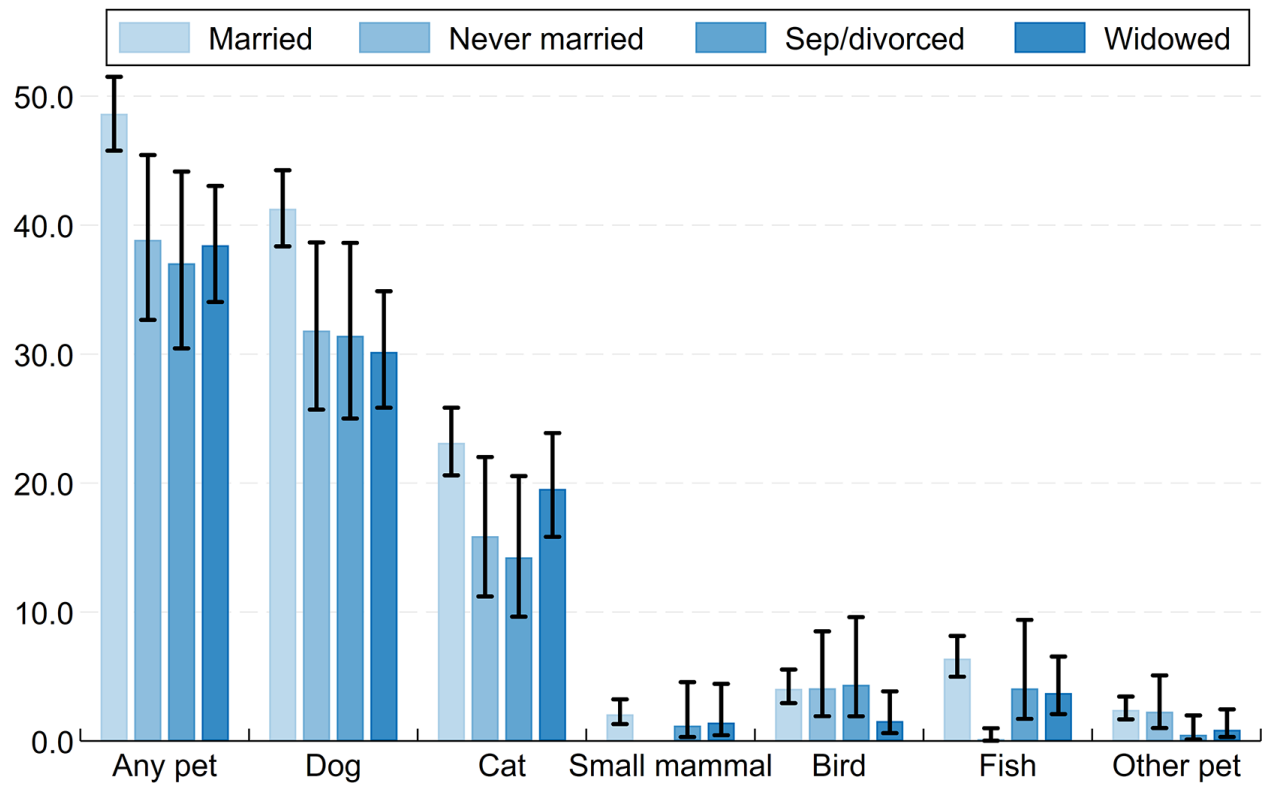

Pet ownership also varies by location (Figure 3) with adults living in rural areas more likely to report having a pet $(57.7 \%)$ compared to those in Dublin city or county $(31.9 \%)$ or other towns/cities (40.2\%). This difference was evident for dogs, cats and other animals (which mostly comprised of horses or donkeys) but not for small mammals, birds or fish.

Figure 3. Pet ownership, by local area

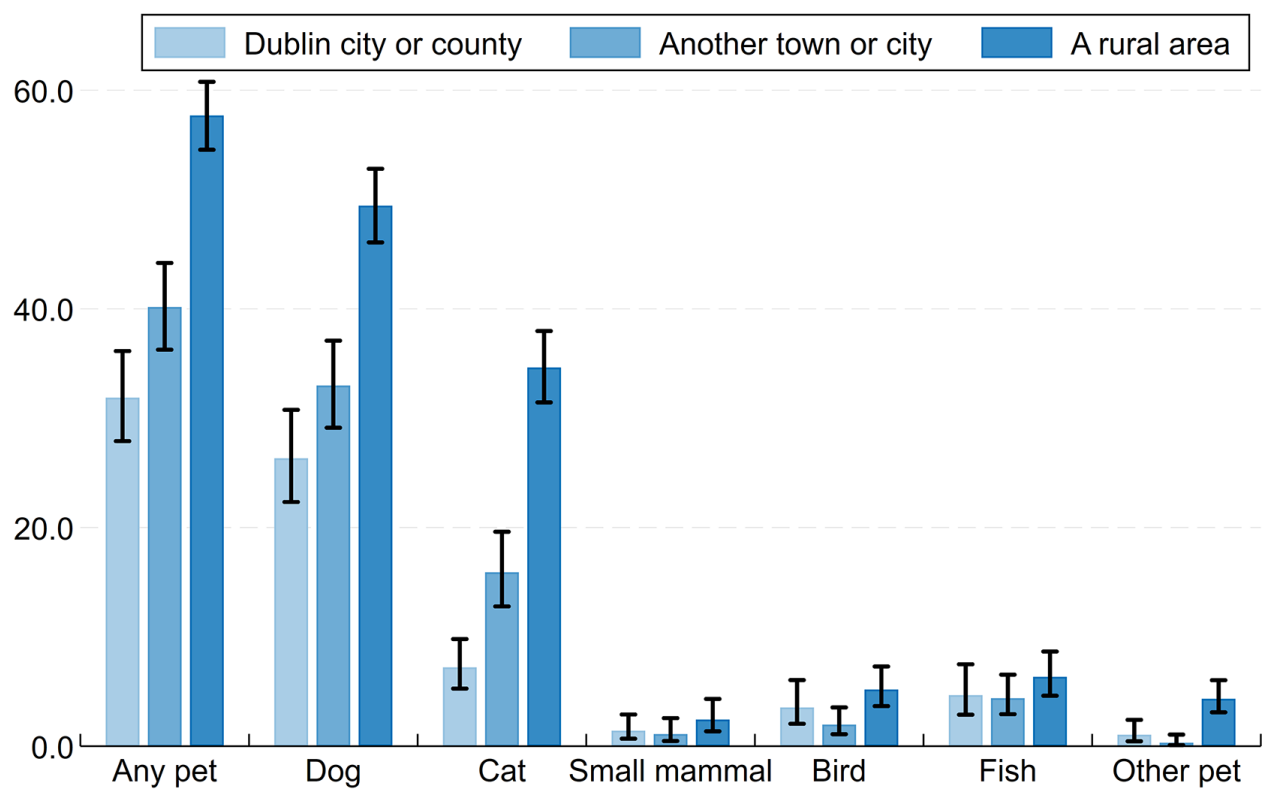


Two-thirds $(65.8 \%)$ of pet owners report having a pet for at least 6 years with a further $21.7 \%$ having a pet for between 3 and 5 years.

\subsection{Dog ownership relative to other pet owners and non-pet owners}

The remainder of this report examines the specific impact of dog ownership on indicators of physical health, social participation and mental health and wellbeing. For these analyses, participants are divided into three groups: (i) non-pet owners $(n=2,269)$, (ii) dog owners, regardless of any other pets $(n=1,480)$, (iii) other pet owners but not dog owners $(n=437)$.

\subsection{Sub-group analysis - regular dog walkers}

Christian and colleagues (9) highlighted the importance of distinguishing between dog owners who do and do not walk their dogs. The frequency with which dog owners walk their dogs is shown in Figure 4. Almost two-fifths (37.9\%) of dog owners report walking their dogs seven days per week.

Figure 4. Number of days per week that dog owners walk their dogs

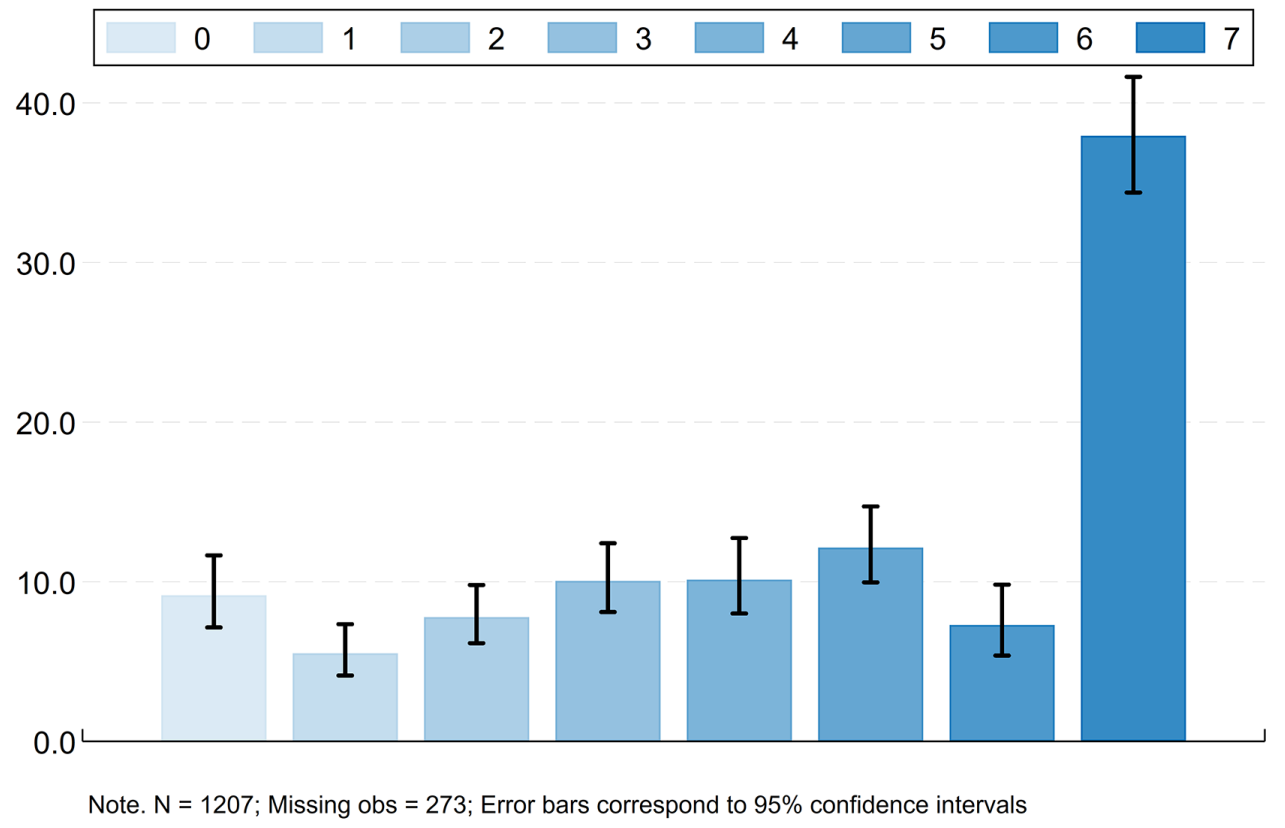


For further analysis, dog owners are categorised into two groups reflecting regular dog walkers (minimum of three days per week) and non-regular dog walkers (less than three days per week). Overall, $77.6 \%$ of dog owners walk their dog at least three times per week, however there are some gender differences. In men aged 50-64 years, 66.5\% walk their dog at least three times per week compared to $83.5 \%$ of men aged $65-74$ years (Figure 5). Four of every five women report walking their dog at least three times per week, across all age groups.

Figure 5. Frequency of dog walking, by age group and sex (among dog walkers)

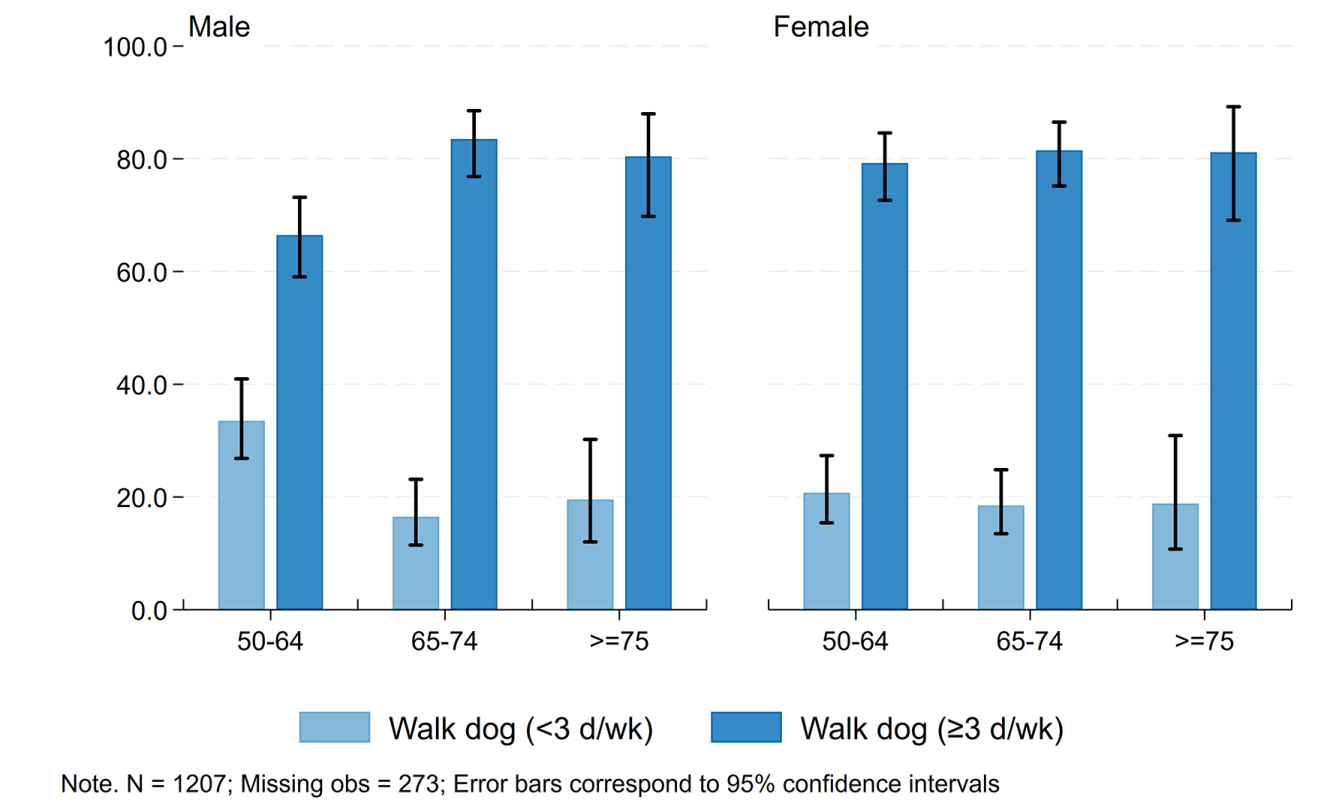

Female 


\section{Dog ownership and physical, behavioural and functional health}

\subsection{Dog ownership, regular dog walking and self-rated health}

A high proportion of adults aged 50 years and over rate their health as good, very good or excellent $(83.1 \%)$ and this is consistent in the dog owner, other pet owner and non-pet owner groups. There is also no overall difference in self-rated health between dog owners who do and do not walk their dogs regularly. However, a difference is observed in adults aged 75 years and over (Figure 6) - a higher proportion of those who regularly walk their dog rate their health as good, very good or excellent compared to non-regular dog walkers (86.3 versus $57.9 \%)$.

Figure 6. Self-rated health, by dog walking frequency and age group (among dog owners)

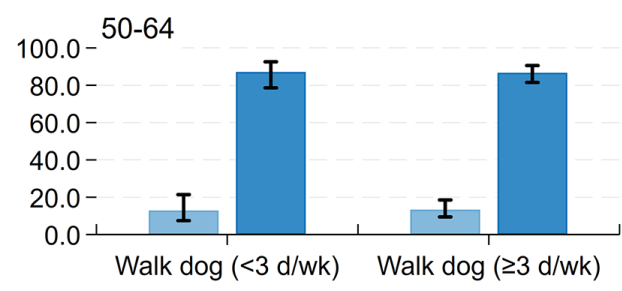

$65-74$
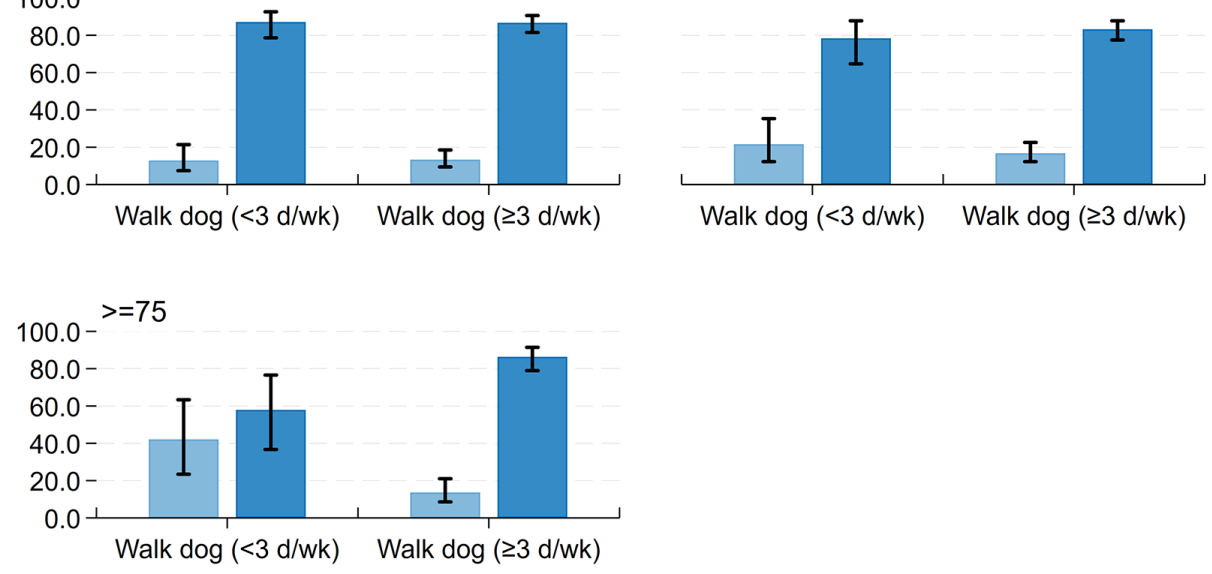

Fair/Poor

Good-Excellent

Note. $N=1207$; Missing obs = 273; Error bars correspond to $95 \%$ confidence intervals

\subsection{Dog ownership, regular dog walking and self-rated health}

Several studies have reported that interactions with dogs are associated with lower blood pressure although the literature is conflicting. In 2013, the American Heart Association stated that pet ownership, and particularly dog ownership, is probably associated with 
decreased risk of cardiovascular disease although the decision to get a dog should not be based on this reason alone (14). In TILDA, hypertension was identified from either self-reported doctor diagnosis of high blood pressure or regular use of antihypertensive medications. Hypertension was common in this group $(52.2 \%)$ but it was relatively consistent in dog owners, other pet owners and non-pet owners. However, there was a trend for hypertension prevalence to be lower in female dog owners $(45.4 \%)$ compared to other pet owners (56.3\%), see Figure 7.

Figure 7. Prevalence of hypertension, by pet ownership and sex

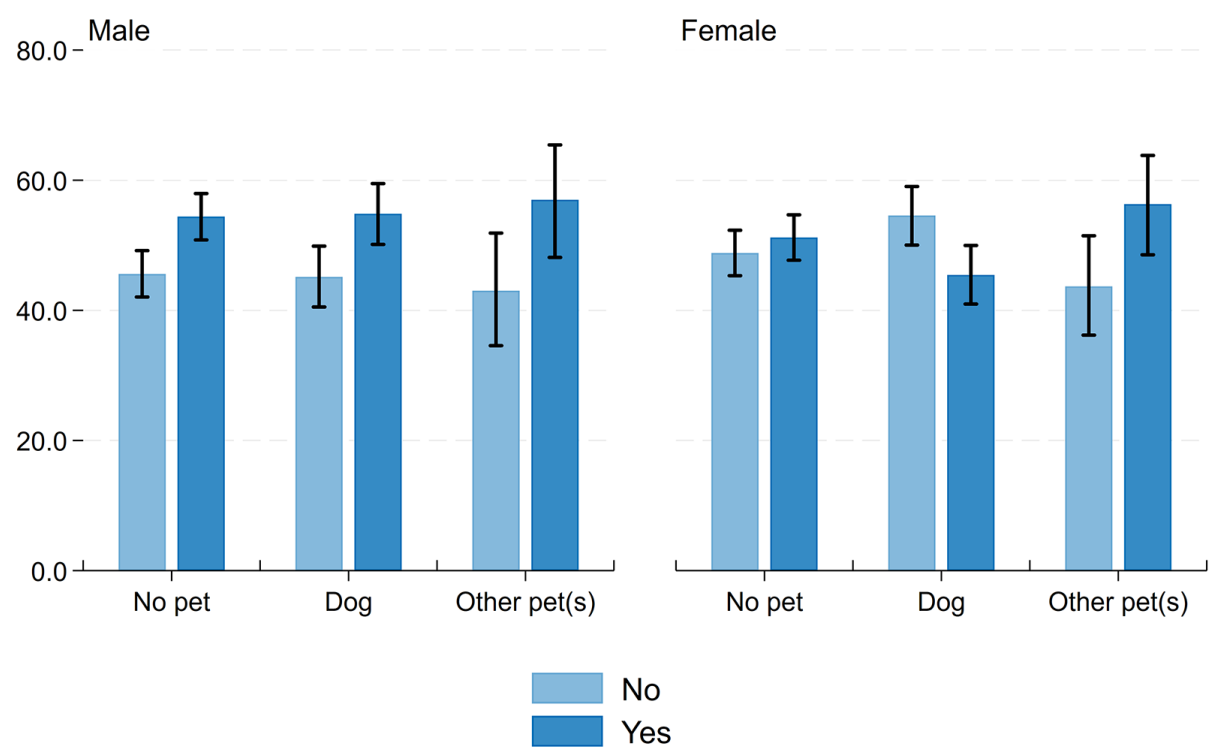

Note. $\mathrm{N}=4186$; Missing obs $=6$; Error bars correspond to $95 \%$ confidence intervals

\subsection{Dog ownership, regular dog walking and physical activity}

In TILDA, physical activity is measured using the short form International Physical Activity Questionnaire (IPAQ). Respondents were asked to indicate the number of days and typical time per day spent walking and doing physical activities of vigorous or moderate intensity during the last week (15). Vigorous activities require hard physical effort, resulting in breathing much harder than normal and can include heavy lifting, digging, aerobics or fast cycling. Moderate activities require moderate physical effort resulting in breathing somewhat harder than normal, for example carrying light loads, cycling at regular pace or doubles tennis. The total time spent in each activity is weighted based on the energy requirements of the activity giving a score in MET-minutes/week for each respondent. They are then classified as having High, Moderate or Low Activity levels based on the criteria in Table 2 (16). 
Table 2: Physical Activity Classifications

\begin{tabular}{l|l}
\hline $\begin{array}{l}\text { Any one of the following } 2 \text { criteria: } \\
\text { - Vigorous intensity activity on } 3 \text { or more days per week } \\
\text { accumulating at least } 1500 \text { MET-minutes/week } \\
\text { OR } \\
\text { - Any combination of walking, moderate or vigorous } \\
\text { intensity activities on } 7 \text { days per week accumulating at } \\
\text { least } 3000 \text { MET-minutes/week }\end{array}$ \\
\begin{tabular}{l} 
Any one of the following 3 criteria: \\
- Vigorous intensity activity of at least 20 minutes on 3 or more \\
days per week \\
OR \\
- Moderate intensity activity of at least 30 minutes on 5 or \\
more days per week \\
OR \\
\hline Moderate Activity \\
- Any combination of walking, moderate or vigorous \\
intensity activities on 5 or more days per week \\
accumulating at least 600 MET-minutes/week
\end{tabular} \\
\begin{tabular}{l} 
Meeting none of the criteria for high or moderate activity \\
\hline Low Activity
\end{tabular}
\end{tabular}

Dog owners are more likely to report high levels of physical activity (33.2\%) compared to those who own no pets $(23.8 \%)$ or other pets $(21.5 \%)$. There are substantial gender effects with women less likely to report high levels and more likely to report low levels of physical activity than men regardless of pet ownership. However, the high levels reported by dog owners compared to non-pet owners is evident in both men (42.6\% versus $31.6 \%)$ and women $(24.1 \%$ versus $16.6 \%)$, see Figure 8. 
Figure 8. Physical activity levels, by pet ownership and sex

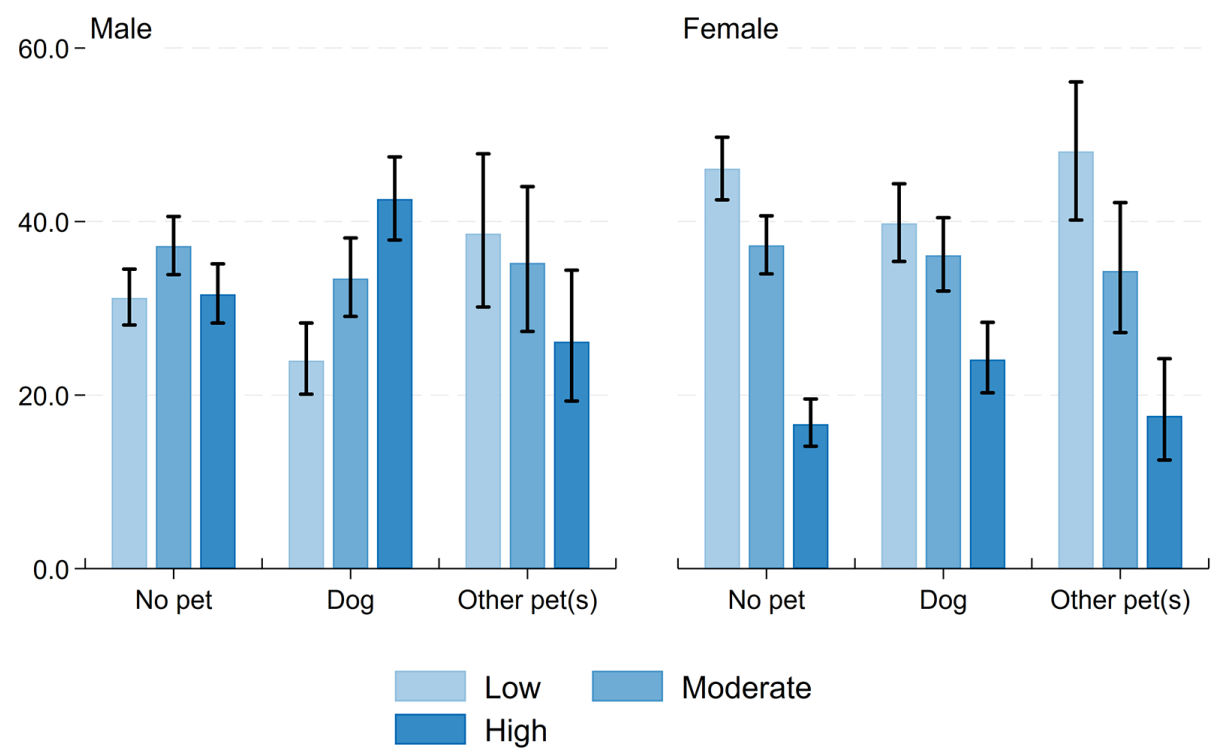

Note. $\mathrm{N}=4170$; Missing obs = 22; Error bars correspond to $95 \%$ confidence intervals

Dog owners who report regularly walking their dogs are more likely to report moderate levels and less likely to report low levels of physical activity. This is particularly evident in women where $30.2 \%$ of regular dog walkers report low physical activity compared to $61.2 \%$ of non-regular dog walkers (Figure 9).

Figure 9. Physical activity levels, by dog walking frequency and sex (among dog owners)

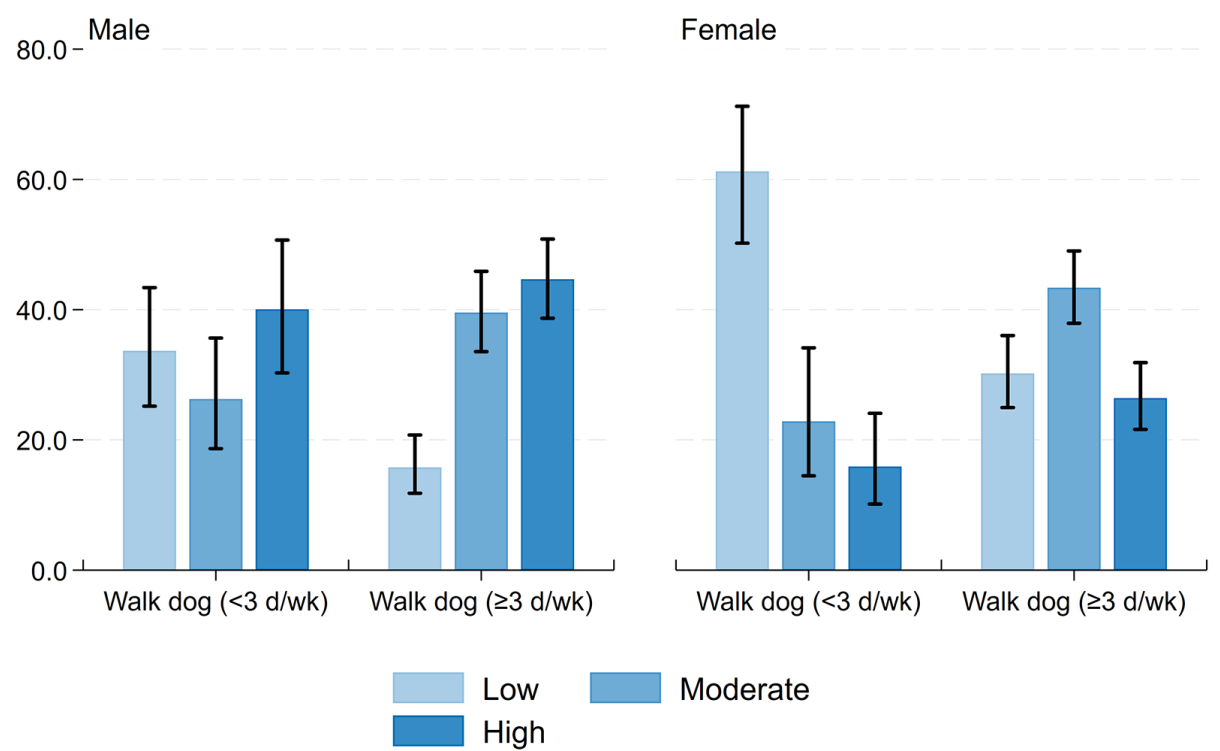

Note. $\mathrm{N}=1200$; Missing obs $=280$; Error bars correspond to $95 \%$ confidence intervals 


\subsection{Dog ownership, regular dog walking and recommended walking levels}

Rating activities as either moderate or vigorous intensity is a very subjective approach and previous research suggests that some older adults have difficulty doing this (7). For example, respondents may rate the intensity of activity according to varying criteria including changes to breathing, sweating, feeling hot or even disliking the activity (17). However, physical activity can be obtained through a range of activities $(18,19)$ and brisk walking for 150 minutes per week is sufficient to meet the physical activity guidelines. It is also easily accessible for all, very simple to measure and removes the problems typically associated with categorising activities as moderate and vigorous intensity in the IPAQ. Consequently, we also divided respondents into two categories (High Walking, Low Walking) based on the number of minutes spent walking in the last week (see Table 3).

Table 3: Walking categories based on number of minutes spent walking in the last week

\begin{tabular}{|l|l|}
\hline High Walking & $\begin{array}{l}\geq 150 \text { minutes of walking in the past week in bouts of at } \\
\text { least } 10 \text { minutes, over } 1 \text { or more days }\end{array}$ \\
\hline Low Walking & $<150$ minutes of walking in the past week \\
\hline
\end{tabular}

Three-fifths (58.2\%) of dog owners report achieving the target 150 minutes per week of walking, compared to $51.4 \%$ of those with no pets and $45.4 \%$ of those with other pets. However, this does vary by location with half $(52.5 \%)$ of dog owners in rural areas achieving the target compared to $66.8 \%$ in Dublin and $63.7 \%$ in other towns/cities (Figure 10). 
Figure 10. Walking, by pet ownership and location
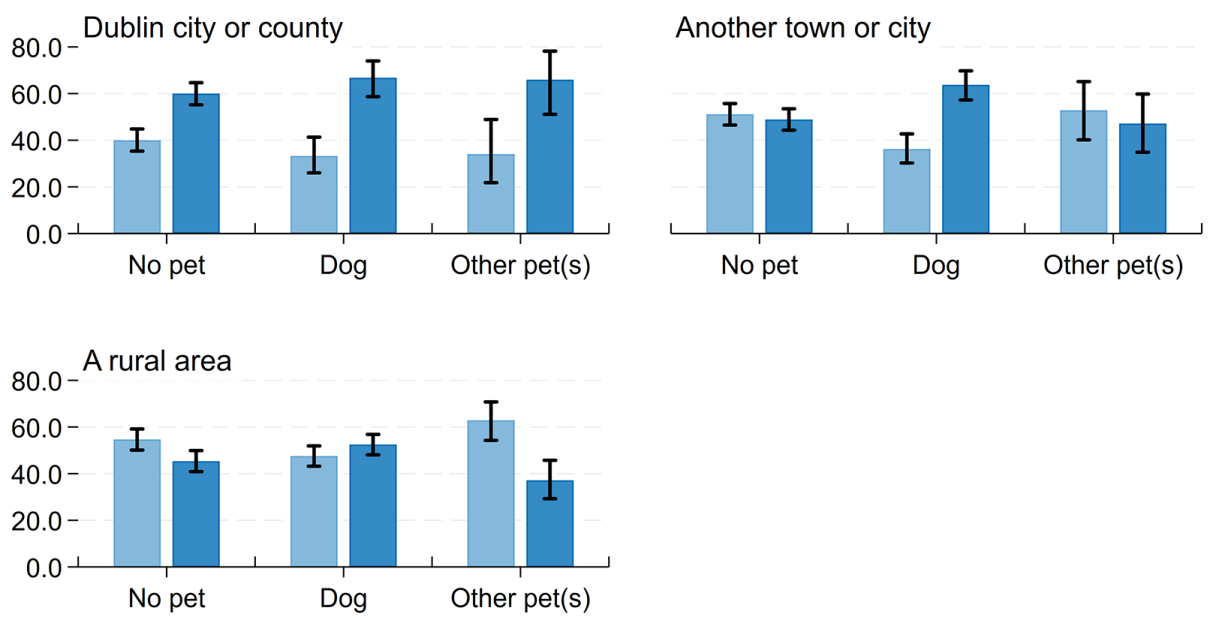

$<150$ mins per week

$\geq 150$ mins per week

Note. $\mathrm{N}=4177$; Missing obs $=15$; Error bars correspond to $95 \%$ confidence intervals

Sub-group analysis showed that dog owners who walk their dog at least 3 days per week are more likely to achieve the target 150 minutes per week of walking compared to those who walk their dog less frequently (68.0\% versus $41.9 \%)$. This pattern was observed in both men and women, however a greater proportion of regular dog walkers in Dublin achieved the target compared to those in rural areas (78.5\% versus $59.9 \%)$.

\subsection{Dog ownership, regular dog walking and smoking}

Dog owners are more likely to report being a current smoker than non-pet owners $(14.6 \%$ versus $10.0 \%$ ). This trend is evident in women but not in men (Figure 11). 
Figure 11. Smoking status, by pet ownership and sex
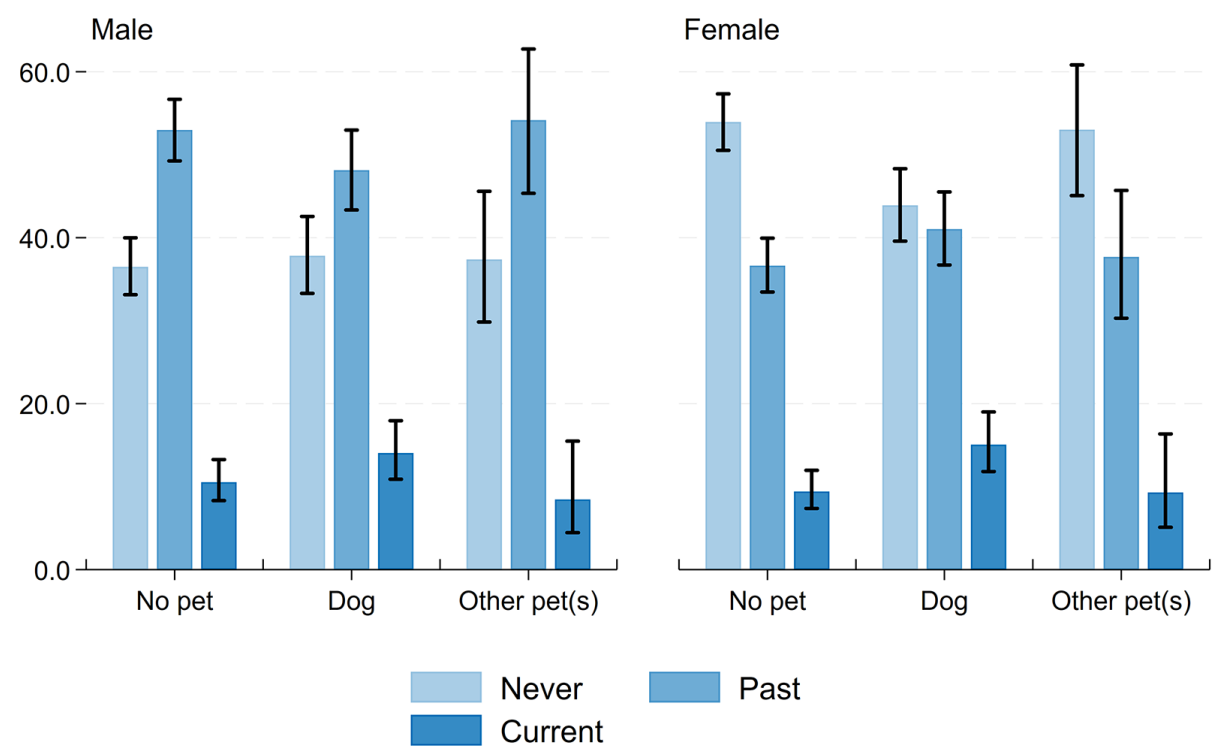

Note. $\mathrm{N}=4183$; Missing obs $=9$; Error bars correspond to $95 \%$ confidence intervals

\subsection{Dog ownership, regular dog walking and body mass index (BMI)}

Height and weight were self-reported during the CAPI. These were used to calculate body mass index (BMI) using the formula: weight in $\mathrm{kg} /$ height in $\mathrm{m}^{2}$. Average $\mathrm{BMI}$ does not differ between dog owners, other pet owners and non-pet owners, however there is a trend for women who are regular dog walkers to have lower BMl compared to women who walk their dog less frequently (26.5 versus $\left.28.3 \mathrm{~kg} / \mathrm{m}^{2}\right)$.

\subsection{Dog ownership, regular dog walking and physical function}

To assess physical function, participants were asked to complete the Timed Up-and-Go (TUG) and hand grip strength tests. TUG is a functional mobility test; participants start in the seated position and are asked to stand up, walk to a line marked 3 metres away on the floor, turn around, walk back to the chair and sit down again. The time taken to complete this task is recorded using a stopwatch. Dog owners have slightly faster TUG than adults who do not own any pets ( 10.5 seconds versus 11.0 seconds) although this is not a substantial difference in performance.

Grip strength was measured using a Baseline $₫$ hand dynamometer. Participants were asked to squeeze the device as hard as possible for a few seconds with mean grip strength calculated from two trials on the dominant hand. Grip strength is higher in those with a dog $(28.7 \mathrm{~kg})$ compared to those with no pets $(26.6 \mathrm{~kg})$. Although grip strength is 
higher in men compared to women (Figure 12), the difference between dog owners and non-pet owners is evident in both men and women (35.9 versus $33.6 \mathrm{~kg}$ in men; 21.2 versus $19.9 \mathrm{~kg}$ in women).

Figure 12. Grip strength (kg), by pet ownership and sex

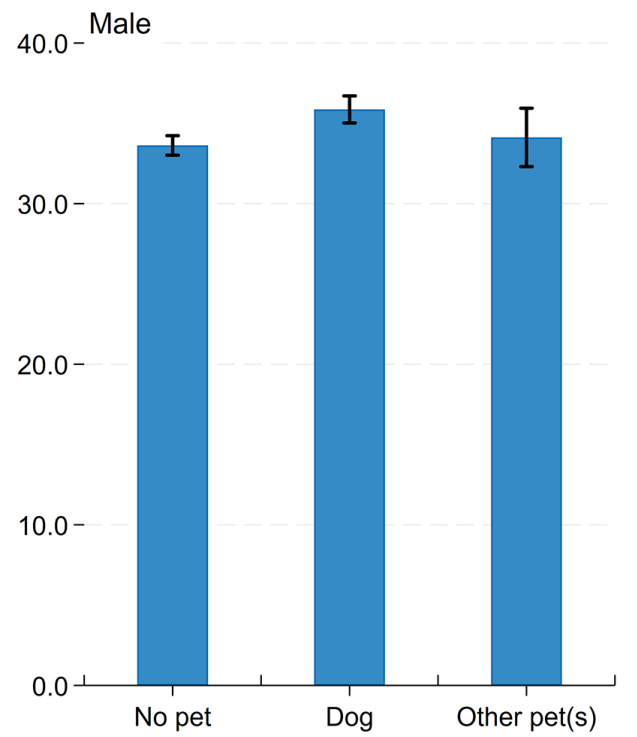

Female

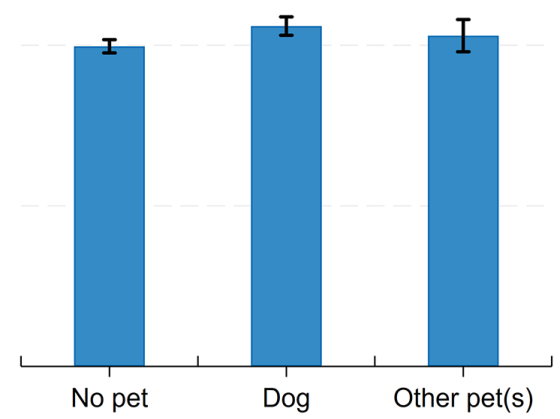

Note. $\mathrm{N}=3835 ;$ Missing obs $=357$; Error bars correspond to $95 \%$ confidence intervals 


\section{Dog ownership and social participation, mental health and wellbeing}

\subsection{Dog ownership, regular dog walking and social participation}

Participation in leisure activities is an important aspect of an individual's social engagement. In TILDA, social participation is measured using a scale proposed by House and colleagues (20). Participants were asked to indicate how often they took part in a range of social activities which were categorised into four groups: (i) close social relationships (including daily visits to or from family and friends); (ii) formal organisational involvements outside of work (such as going to religious services or meetings at voluntary associations at least once a month); (iii) active and relatively social leisure activities (including going to classes, lectures, movies, plays and concerts, playing cards or bingo, eating outside the house or taking part in sports at least once a month); and (iv) passive and relatively solitary leisure activities (such as watching television, listening to the radio, or reading at least once a month).

The majority of adults aged 50 years and over in Ireland take part in active and social leisure pursuits $(79 \%)$ and formal organisations outside of work $(60 \%)$ at least once a month while $42 \%$ report close social relationships. While there is no difference in involvement in active and social leisure pursuits by dog owners compared to those with no pets ( $89 \%$ versus $91 \%$ ), they are less likely to be involved in formal organisations (58\% versus $66 \%$ ), see Figure 13 . Regular dog walkers however, are more likely to report close social relationships (44\% versus $27 \%$ ) and taking part in active and social leisure activities in the past month ( $92 \%$ versus $86 \%$ ) than dog owners who walk their dog less frequently. The higher close social relationships among regular dog walkers was particularly evident in men (Figure 14). 
Figure 13. Social participation, by pet ownership

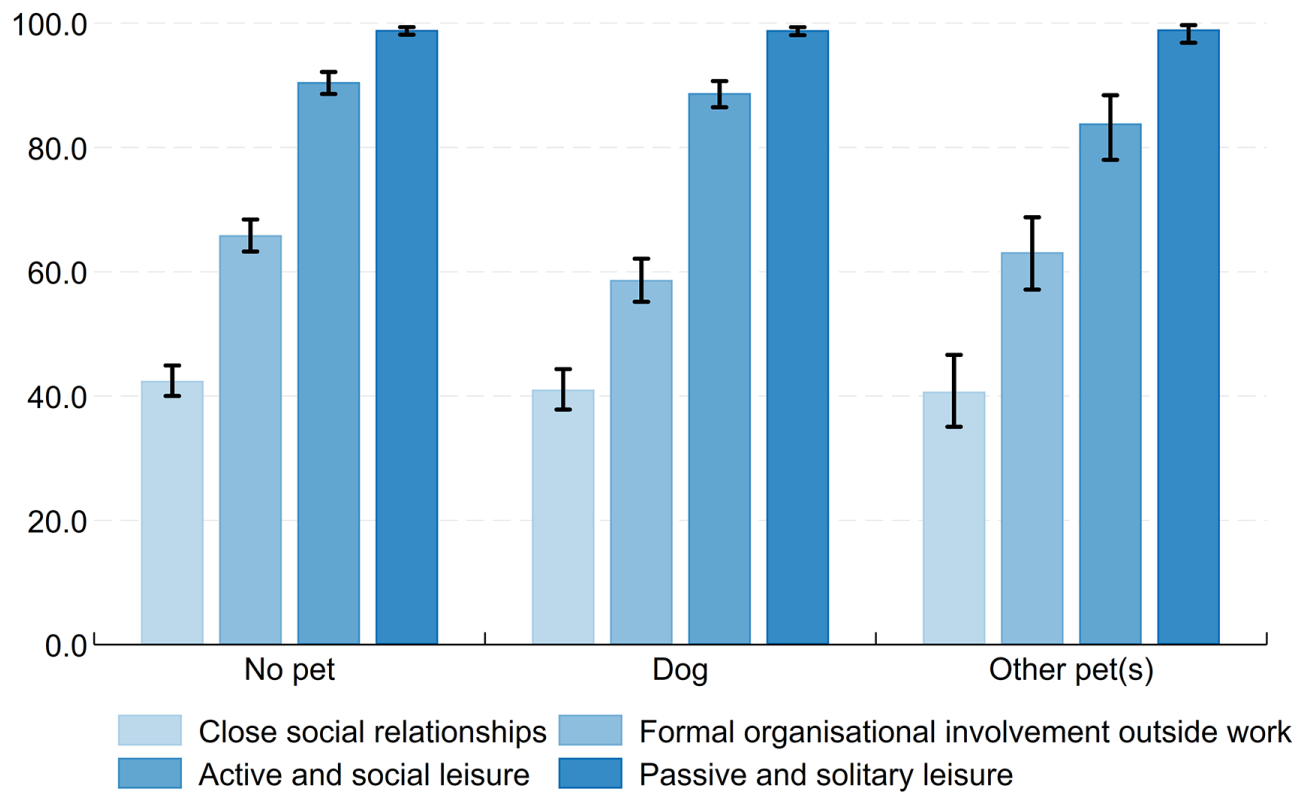

Note. $N=4116$; Missing obs = 76; Error bars correspond to $95 \%$ confidence intervals

Figure 14. Social participation, by dog walking frequency and sex (among dog owners)
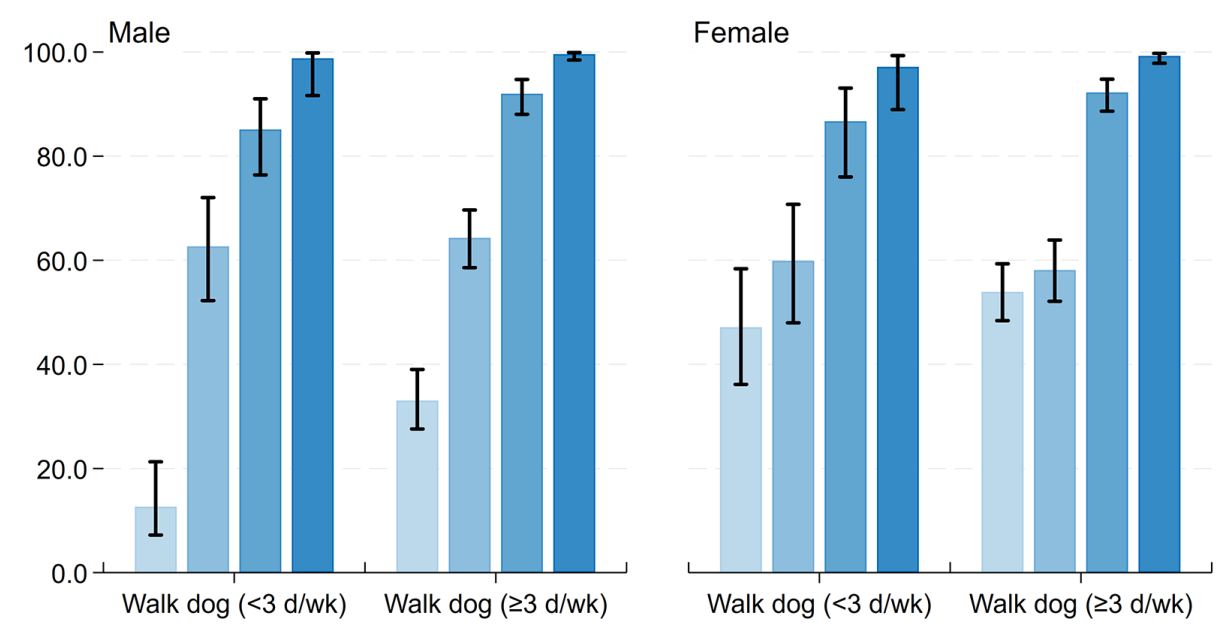

Close social relationships Formal organisational involvement outside work Active and social leisure Passive and solitary leisure

Note. $\mathrm{N}=1188$; Missing obs $=292$; Error bars correspond to $95 \%$ confidence intervals

5.2 Dog ownership, regular dog walking and depressive symptoms, quality of life, loneliness and sense of purpose

Research on pet ownership and mental health is conflicting with some studies reporting associations with positive mental health, a reduction in loneliness and increased wellbeing 
$(5,21)$ and others reporting higher depressive symptoms and loneliness $(2,8)$. The pathway through which wellbeing could be improved may be through companionship, or taking care of pets.

In TILDA, depressive symptoms are measured using the Centre for Epidemiologic Studies Depression (CES-D) scale. This is a 4-point scale where participants rate how often they experienced each of 8 depressive symptoms over the past week (22). While depressive symptoms are higher in women than men, there is no evidence of a difference in CES-D scores by pet ownership or in regular dog walkers compared to those who walk their dog less frequently.

Quality of life reflects the general wellbeing of an individual and is measured in TILDA using the CASP-12 scale. This includes 12 items that cover four main areas: control (the ability to actively participate in one's environment), autonomy (the right of an individual to be free from the unwanted interference from others), self-realisation (the fulfilment of one's potential) and pleasure (the sense of happiness or enjoyment that one derives from engaging with life). Item scores are summed to give an overall score ranging from 0-36 with higher scores indicating better quality of life (23). There were no differences in CASP-12 scores in dog owners compared to those who have no pets or in regular dog walkers compared to non-regular dog walkers.

Loneliness reflects an individual's evaluation of their overall level of social interaction, and describes a deficit between the actual and desired quality and quantity of social engagement (24). It has been associated with declines in physical, mental and cognitive health in older adults (25). In TILDA, loneliness is measured using a modified version of the University of California-Los Angeles (UCLA) Loneliness scale (26). This version includes five items, each with three response options (hardly ever or never, some of the time, often). Responses are summed with the overall score ranging from 0 (not lonely) to 10 (extremely lonely). Overall, loneliness scores are low and are similar for dog owners and adults with no pets and also between the regular and non-regular dog walkers. However, adults who own pets other than a dog have higher loneliness scores (2.1) compared to dog owners and those with no pets (1.62 in both).

Purpose in life was measured using Ryff's Purpose in Life sub-scale. This is a 7 question scale designed to determine if the person has clear goals and is able to define goals in their life (27). Respondents were asked to indicate if a statement described them accurately or not using a 6-point answering scale, ranging from strongly agree to strongly disagree. Responses are summed with the overall score ranging from 0 (low purpose) to 15 (high purpose). The scale is interpreted as follows: a high scorer has goals in life and 
a sense of directedness; feels there is meaning to present and past life; holds beliefs that give life purpose; has aims and objectives for living. In contrast, a low scorer lacks a sense of meaning in life; has few goals or aims, lacks sense of direction; does not see purpose of past life; has no outlook or beliefs that give life meaning. Older adults have a relatively high sense of purpose in life overall, and this does not vary by pet ownership or regular dog walking.

\subsection{Reason for pet ownership and depressive symptoms, quality of life, loneliness and sense of purpose}

Participants were asked to indicate their reasons for having a pet using the list provided (Table 4). The majority of pet owners report that they have a pet because they love animals (79\%) and for companionship (64\%) while protection, wanting to care for something, maintaining activity levels, and being given a pet were also commonly cited reasons.

Table 4. Proportion of men and women reporting the following reasons for having a pet

\begin{tabular}{|l|c|c|}
\hline & Men & Women \\
\hline Enjoyment (love animals) & 81.2 & 77.8 \\
\hline Protection & 24.6 & 28.2 \\
\hline Companionship & 66.6 & 62.6 \\
\hline Playmate for child & 13.4 & 9.3 \\
\hline Want something I could take care of & 33.3 & 29.9 \\
\hline Want something to keep me busy (occupy the time) & 26.6 & 21.4 \\
\hline Want something to keep me active (get exercise) & 38.3 & 39.3 \\
\hline Therapy (e.g. guide dog) & 4.2 & 4.4 \\
\hline Was given the pet & 31.7 & 26.0 \\
\hline
\end{tabular}

Wellbeing and mental health outcomes differ in pet owners depending on the reason they state for having a pet. Table 5 shows that adults who report loving animals have a higher sense of purpose in life compared to those who did not report this reason. However, some reasons for having a pet were associated with poorer mental health and wellbeing. Adults who state that they have a pet for something to take care of, to keep busy or because they were given a pet, all have lower purpose in life scores than those who do not report these as a reason for having a pet. Those who state that they want something to take care of, or were given a pet, also have lower quality of life scores while pet owners who indicate that the reason they have a pet is either to keep busy, or for therapy, have increased loneliness scores. 
Table 5. Mental health and wellbeing measures, by reason for pet ownership
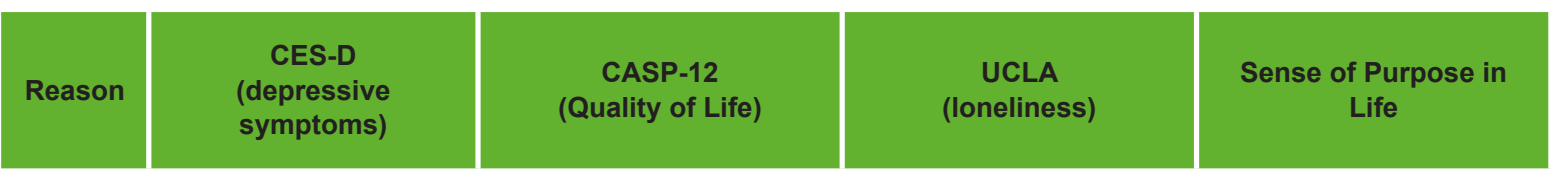
$N \quad \begin{gathered}\text { Mean } \\ (95 \% \mathrm{Cl})\end{gathered}$
N $\begin{gathered}\text { Mean } \\ (95 \% \mathrm{Cl})\end{gathered}$
Mean
$(95 \% \mathrm{Cl})$
N $\begin{gathered}\text { Mean } \\ (95 \% \mathrm{Cl})\end{gathered}$

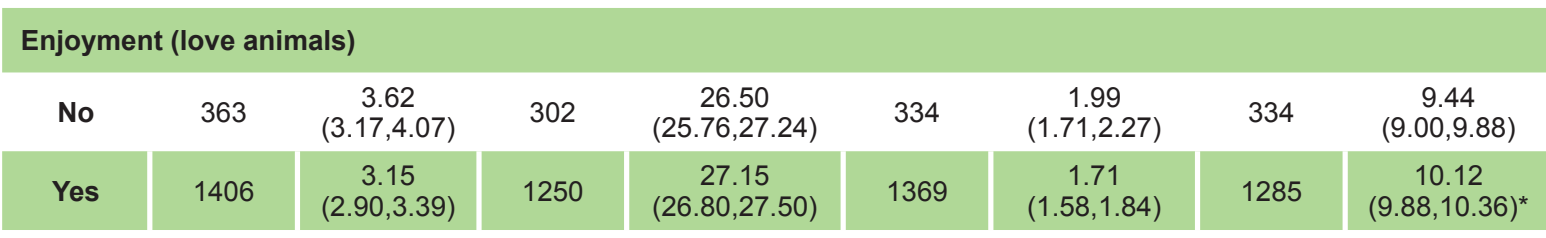

\section{Protection}

\begin{tabular}{|c|c|c|c|c|c|c|c|c|}
\hline No & 1305 & $\begin{array}{c}3.33 \\
(3.07,3.59)\end{array}$ & 1158 & $\begin{array}{c}26.85 \\
(26.47,27.2)\end{array}$ & 1254 & $\begin{array}{c}1.82 \\
(1.67,1.97)\end{array}$ & 1195 & $\begin{array}{c}10.03 \\
(9.80,10.26)\end{array}$ \\
\hline Yes & 464 & $\begin{array}{c}3.01 \\
(2.62,3.40)\end{array}$ & 394 & $\begin{array}{c}27.54 \\
(26.90,28.17)\end{array}$ & 449 & $\begin{array}{c}1.60 \\
(1.40,1.79)\end{array}$ & 424 & $\begin{array}{c}9.84 \\
(9.40,10.27)\end{array}$ \\
\hline \multicolumn{9}{|c|}{ Companionship } \\
\hline No & 612 & $\begin{array}{c}3.20 \\
(2.88,3.5)\end{array}$ & 522 & $\begin{array}{c}26.73 \\
(26.18,27.28)\end{array}$ & 582 & $\begin{array}{c}1.82 \\
(1.59,2.05)\end{array}$ & 561 & $\begin{array}{c}9.85 \\
(9.48,10.21)\end{array}$ \\
\hline Yes & 1157 & $\begin{array}{c}3.27 \\
(2.99,3.54\end{array}$ & 1030 & $\begin{array}{c}27.17 \\
(26.78,27.57)\end{array}$ & 1121 & $\begin{array}{c}1.73 \\
(1.59,1.87)\end{array}$ & 1058 & $\begin{array}{c}10.05 \\
(9.79,10.31)\end{array}$ \\
\hline
\end{tabular}

Playmate for child

\begin{tabular}{|c|c|c|c|c|c|c|c|c|}
\hline No & 1262 & $\begin{array}{c}3.29 \\
(3.05,3.579\end{array}$ & 1395 & $\begin{array}{c}27.00 \\
(26.65,27.35)\end{array}$ & 1518 & $\begin{array}{c}1.78 \\
(1.65,1.91)\end{array}$ & 1450 & $\begin{array}{c}10.05 \\
(9.83,10.26)\end{array}$ \\
\hline Yes & 190 & $\begin{array}{c}2.90 \\
(2.24,3.56)\end{array}$ & 157 & $\begin{array}{c}27.22 \\
(26.16,28.29)\end{array}$ & 185 & $\begin{array}{c}1.62 \\
(1.26,1.99)\end{array}$ & 169 & $(8.43,10.19)$ \\
\hline
\end{tabular}

\section{Keep Busy (Occupy myself)}

\begin{tabular}{|c|c|c|c|c|c|c|c|c|}
\hline No & 1381 & $\begin{array}{c}3.21 \\
(2.97,3.46)\end{array}$ & 1223 & $\begin{array}{c}27.20 \\
(26.83,27.57)\end{array}$ & 1331 & $\begin{array}{c}1.69 \\
(1.55,1.83)\end{array}$ & 1275 & $\begin{array}{c}10.18 \\
(9.96,10.40)\end{array}$ \\
\hline Yes & 388 & $\begin{array}{c}3.34 \\
(2.88,3.81)\end{array}$ & 329 & $\begin{array}{c}26.41 \\
(25.70,27.13)\end{array}$ & 372 & $\begin{array}{c}1.99 \\
(1.74,2.23)^{*}\end{array}$ & 344 & $\begin{array}{c}9.31 \\
(8.83,9.78)^{\star \star}\end{array}$ \\
\hline \multicolumn{9}{|c|}{ Keep Active (get exercise) } \\
\hline No & 1095 & $\begin{array}{c}3.27 \\
(3.00,3.54)\end{array}$ & 961 & $\begin{array}{c}27.02 \\
(26.60,27.43)\end{array}$ & 1056 & $\begin{array}{c}1.85 \\
(1.69,2.01)\end{array}$ & 1007 & $\begin{array}{c}10.09 \\
(9.83,10.35)\end{array}$ \\
\hline Yes & 674 & $\begin{array}{c}3.20 \\
(2.85,3.56)\end{array}$ & 591 & $\begin{array}{c}27.02 \\
(26.52,27.53)\end{array}$ & 647 & $\begin{array}{c}1.63 \\
(1.45,1.80)\end{array}$ & 612 & $\begin{array}{c}9.80 \\
(9.44,10.17)\end{array}$ \\
\hline
\end{tabular}

Therapy (e.g. guide dog)

\begin{tabular}{|c|c|c|c|c|c|c|c|c|}
\hline No & 1689 & $\begin{array}{c}3.22 \\
(2.99,3.44)\end{array}$ & 1482 & $\begin{array}{c}27.08 \\
(26.74,27.42)\end{array}$ & 1625 & $\begin{array}{c}1.74 \\
(1.62,1.87)\end{array}$ & 1544 & $\begin{array}{c}10.02 \\
(9.81,10.22)\end{array}$ \\
\hline Yes & 79 & $\begin{array}{c}3.83 \\
(2.86,4.81)\end{array}$ & 69 & $\begin{array}{c}25.75 \\
(23.83,27.32)\end{array}$ & 77 & $\begin{array}{c}2.25 \\
(1.79,2.70)^{*}\end{array}$ & 74 & $\begin{array}{c}9.19 \\
(8.06,10.31\end{array}$ \\
\hline \multicolumn{9}{|c|}{ Given pet } \\
\hline No & 1265 & $\begin{array}{c}3.18 \\
(2.91,3.45)\end{array}$ & 1116 & $\begin{array}{c}27.25 \\
(26.86,27.64)\end{array}$ & 1222 & $\begin{array}{c}1.75 \\
(1.60,1.89)\end{array}$ & 1163 & $\begin{array}{c}10.16 \\
(9.93,10.40)\end{array}$ \\
\hline Yes & 504 & $\begin{array}{c}3.41 \\
(3.04,3.77)\end{array}$ & 436 & $\begin{array}{c}26.44 \\
(25.88,27.01)^{*}\end{array}$ & 481 & $\begin{array}{c}1.80 \\
(1.59,2.02)\end{array}$ & 456 & $\begin{array}{c}9.53 \\
(9.13,9.93)^{\star *}\end{array}$ \\
\hline
\end{tabular}

Note: F-test for difference; ${ }^{*} p<0.05,{ }^{* *} p<0.01,{ }^{* * *} p<0.001$ 


\section{Conclusions}

This report shows that $45.3 \%$ of community-dwelling adults aged 50 years and older in Ireland have a pet with $38.0 \%$ and $21.2 \%$ reporting having a dog and cat respectively. This is similar to population based studies carried out in adults of similar age in the United Kingdom and the United States where pet ownership levels of 39\% (2) and 51.5\% (1) respectively were reported. However, pet ownership declines with increasing age from $56.8 \%$ in those aged $50-64$ years to $32.9 \%$ in those aged 75 and over and is higher for those living in rural areas.

Many dog owners report a strong connection and bond with their dogs and make every effort to ensure the health and happiness of their pet. Therefore, it is not surprising that $77.6 \%$ report that they walk their dog at least three times per week. Men aged 50-64 years are less likely to do so compared to other age groups, but this may reflect the higher proportion of this group who are working and therefore, they may have less available time to do so. Consequently, dog owners are more likely to report high levels of physical activity and to meet the recommended walking target of 150 minutes per week compared to nondog owners. They also demonstrate higher hand grip strength, reflecting better overall body strength and a trend for faster mobility performance. While female dog owners are more likely to be current smokers, those who walk their dog regularly have lower BMI based on self-reported height and weight compared to non-regular dog walkers.

This supports previous research which showed that dog owners, and particularly dog walkers, report higher levels of physical activity compared to non-dog owners (9). There is strong evidence supporting the health benefits of physical activity in adults aged 65 years and over, which include increased cardiorespiratory and muscle fitness, lower body fat, a more favourable metabolic profile, lower rates of cardiovascular disease (including high blood pressure, stroke, type 2 diabetes), cancer (colon and breast), and all-cause mortality, better cognitive function, better functional health and lower risk of falling (19). Continued participation in community and leisure pursuits outside of the home is also important and provides both health and social benefits $(28,29)$ and a physically active lifestyle can increase wellbeing, particularly improving mental health and quality of life (30). Although overall, there is no benefit in pet ownership for mental health and wellbeing outcomes, 
regular dog walkers do report higher active social participation and more close social relationships than dog owners who walk their dog less frequently

The Get Ireland Active (31) and Get Ireland Walking (32) initiatives aim to increase the number of Irish people of all ages who take part in physical activity and/or walking for fitness, health and wellbeing benefits. This data cannot indicate if dog ownership causes increased physical activity or if more physically active individuals are more likely to have a dog, however it does indicate that there are positive associations between dog ownership and dog walking with physical activity levels. The effect of location may be an important consideration here as adults in Dublin are more likely to reach the walking target compared to those in rural areas. This could be due to a number of reasons including the higher proportion of working dogs in rural areas, larger gardens/space for dogs to run around thus requiring less dedicated walking time or better walking facilities available in urban areas.

However, given the high prevalence of dog ownership, the strong attachment between dogs and their owners and the physical activity requirements to promote dog health, this may represent a useful strategy to promote physical activity for their owners. Westgarth and colleagues (33) suggest that the most effective ways to encourage dog walking include focusing on the dog-owner relationship, particularly the emotional support that a dog provides and the sense of obligation to walk the dog; and also by providing suitable and accessible physical environments that are supportive of dogs, allow off-leash walking and promote social interactions. Facilitating dog ownership for longer and/or providing care for a family member or neighbour's dog may also encourage greater physical activity levels.

The majority of pet owners report that they love their pets and this group have a higher sense of purpose in life. These findings support previous research in which dog owners felt that they had a responsibility to provide sufficient exercise for their dog to provide physical and mental health benefits (11). However, other reasons for pet ownership, including 'wanting to have something to take care of' and 'to keep busy' were associated with poorer wellbeing measures including increased loneliness, lower quality of life and a lower sense of purpose in life. This likely indicates that the purpose of the pet was to help alleviate lower mood and loneliness, rather than low mood being caused by pet ownership. This concurs with research from the English Longitudinal Study on Ageing (ELSA) that found a bi-directional relationship between pet ownership and loneliness (2), although other research has suggested that pet ownership may attenuate loneliness in older adults living alone (5). It is possible that these psychological benefits result from greater attachment 
and love for the pet which is further facilitated by the health and functional benefits accrued through ensuring the pet has sufficient physical activity to maintain the pet's health. However, these results highlight the complex relationship between pet owners and their health and wellbeing and that the reason for pet ownership may explain some of the differences seen in existing research.

A number of mechanisms have been proposed to explain the beneficial effects of pet exposure or ownership. Beetz and colleagues (34) proposed that tactile interactions with animals release a hormone called oxytocin, which is associated with many positive effects including decreased stress and anxiety. Goetz and colleagues (35) also propose that feelings of warmth and tenderness may lead to stress reduction by increasing activity in the parasympathetic nervous system. This system is responsible for decreasing heart rate and respiration and increasing digestion when the body is in a relaxed or resting state. Walking with a dog and indeed, interacting with a dog at home, has also been shown to increase activity in the parasympathetic nervous system (36).

There are some limitations to this analysis. Firstly, the data is cross-sectional so we cannot identify if dog ownership leads to social, physical and mental health benefits; if healthier individuals are more likely to have a dog as this fits within their healthier lifestyle; or if those in poorer health are more likely to get a dog for companionship. Predictors of having a dog are often associated with positive health outcomes so it can be difficult to disentangle this relationship. Multiple waves of data about pet ownership and subsequent health and function is required to examine these causal pathways and this will be examined in future research. The duration, distance or speed of walking with a dog was not measured although walking patterns can range from continuous brisk walking to slow walking or even standing while a dog investigates the surroundings. The age, breed and health of the dog can influence dog walking requirements, but this was also not available. Finally, physical activity was self-reported; objective measurements obtained using accelerometers or other devices would provide more accurate physical activity data.

Regardless of these limitations, there is evidence that exposure to a dog plays a role in enhancing an individual's holistic wellbeing, therefore it may represent a strategy to promote positive physical and mental health effects. Possible opportunities include volunteering at local animal shelters, providing 'daycare' for dogs whose owners are at work during the day, dog visiting programmes for older adults living at home, dogs accompanying home care professionals, or resident dogs or other animals in nursing homes, all of which would increase exposure and interactions with pets without the added responsibility of full-time ownership (37). 
In conclusion, dog owners report higher levels of physical activity and better physical function compared to non-dog owners and those who walk their dog at least three times per week report greater active social participation and close social relationships, compared to those who walk their dog less frequently. The reason for owning a pet explains some of the different mental health and wellbeing outcomes seen in previous research. To maintain wellbeing in older adults and to support independent ageing at home, it will be important to consider the potential benefits of exposure to and interaction with pets and consequently, innovative ways which facilitate older adults to keep pets for as long as they wish to do so, in order to increase opportunities for active and healthy ageing. This is especially pertinent given the current changing population demographics in Ireland. 


\section{References}

1. Mueller MK, Gee NR, Bures RM. Human-animal interaction as a social determinant of health: descriptive findings from the health and retirement study. BMC Public Health. 2018;18(1):305.

2. Pikhartova J, Bowling A, Victor C. Does owning a pet protect older people against Ioneliness? BMC Geriatrics. 2014;14:106.

3. Friedmann E, Gee N, Simonsick E, Studenski S. Pet ownership patterns in communityliving older adults. Innov Aging. 2018;2(Suppl 1):974.

4. Enmarker I, Hellzen O, Ekker K, Berg AG. Health in older cat and dog owners: The Nord-Trondelag Health Study (HUNT)-3 study. Scandinavian Journal of Public Health. 2012;40(8):718-24.

5. Stanley IH, Conwell Y, Bowen C, Van Orden KA. Pet ownership may attenuate loneliness among older adult primary care patients who live alone. Aging \& Mental Health. 2014;18(3):394-9.

6. Mein G, Grant R. A cross-sectional exploratory analysis between pet ownership, sleep, exercise, health and neighbourhood perceptions: the Whitehall II cohort study. BMC Geriatrics. 2018;18(1):176.

7. Batty GD, Zaninotto P, Watt RG, Bell S. Associations of pet ownership with biomarkers of ageing: population based cohort study. BMJ. 2017;359:j5558.

8. Parslow RA, Jorm AF, Christensen H, Rodgers B, Jacomb P. Pet ownership and health in older adults: findings from a survey of 2,551 community-based Australians aged 6064. Gerontology. 2005;51(1):40-7.

9. Christian HE, Westgarth C, Bauman A, Richards EA, Rhodes RE, Evenson KR, et al. Dog ownership and physical activity: a review of the evidence. Journal of Physical Activity \& Health. 2013;10(5):750-9. 
10. Soares J, Epping JN, Owens CJ, Brown DR, Lankford TJ, Simoes EJ, et al. Odds of Getting Adequate Physical Activity by Dog Walking. Journal of Physical Activity \& Health. 2015;12 Suppl 1(6 0 1):S102-S9.

11. Curl AL, Bibbo J, Johnson RA. Dog Walking, the Human-Animal Bond and Older Adults' Physical Health. The Gerontologist. 2017;57(5):930-9.

12. Central Statistics Office. Projected Population 2006 Based by Sex, Age, Criteria for Projection and Year 2019 [Available from: http://www.cso.ie/px/pxeirestat/Statire/ SelectVarVal/Define.asp?maintable=PEA06].

13. Donoghue OA, McGarrigle CA, Foley M, Fagan A, Meaney J, Kenny RA. Cohort Profile Update: The Irish Longitudinal Study on Ageing (TILDA). International Journal of Epidemiology. 2018;47(5):1398-I.

14. Levine Glenn N, Allen K, Braun Lynne T, Christian Hayley E, Friedmann E, Taubert Kathryn A, et al. Pet Ownership and Cardiovascular Risk. Circulation. 2013;127(23):2353-63.

15. Craig CL, Marshall AL, Sjostrom M, Bauman AE, Booth ML, Ainsworth BE, et al. International physical activity questionnaire: 12-country reliability and validity. Medicine and Science in Sports and Exercise. 2003;35(8):1381-95.

16. IPAQ. Guidelines for the data processing and analysis of the International Physical Activity Questionnaire. 2005.

17. Rzewnicki R, Vanden Auweele Y, De Bourdeaudhuij I. Addressing overreporting on the International Physical Activity Questionnaire (IPAQ) telephone survey with a population sample. Public Health Nutrition. 2003;6(3):299-305.

18. Department of Health and Children HSE. Get Ireland Active Guidelines. 2009 [Available from: http://www.getirelandactive.ie/content/wp-content/uploads/2011/12/ Get-IrelandActive-Guidelines-GIA.pdf].

19. World Health Organisation. Global Recommendations on Physical Activity for Health. 2010. 
20. House JS, Robbins C, Metzner HL. The association of social relationships and activities with mortality: prospective evidence from the Tecumseh Community Health Study. American Journal of Epidemiology. 1982;116(1):123-40.

21. Wells Deborah L. The Effects of Animals on Human Health andWell-Being. Journal of Social Issues. 2009;65(3):523-43.

22. Radloff LS. The CES-D Scale:A Self-Report Depression Scale for Research in the General Population. Applied Psychological Method. 1977;1(3):385-401.

23. Hyde M, Wiggins RD, Higgs $P$, Blane DB. A measure of quality of life in early old age: the theory, development and properties of a needs satisfaction model (CASP-19). Aging \& Mental Health. 2003;7(3):186-94.

24. Victor CR, Scambler SJ, Bowling ANN, Bond J. The prevalence of, and risk factors for, loneliness in later life: a survey of older people in Great Britain. Ageing and Society. 2005;25(6):357-75.

25. Hawkley LC, Cacioppo JT. Loneliness matters: a theoretical and empirical review of consequences and mechanisms. Annals of Behavioral Medicine : a publication of The Society of Behavioral Medicine. 2010;40(2):218-27.

26. Russell DW. UCLA Loneliness Scale (Version 3): reliability, validity, and factor structure. Journal of Personality Assessment. 1996;66(1):20-40.

27. Ryff CD, Keyes CL. The structure of psychological well-being revisited. Journal of Personality and Social Psychology. 1995;69(4):719-27.

28. House JS, Landis KR, Umberson D. Social relationships and health. Science (New York, NY). 1988;241(4865):540-5.

29. Siegrist J, Wahrendorf M. Participation in socially productive activities and quality of life in early old age: findings from SHARE. Journal of European Social Policy. 2009;19(4):317-26. 
30. Chodzko-Zajko WJ, Proctor DN, Fiatarone Singh MA, Minson CT, Nigg CR, Salem GJ, et al. American College of Sports Medicine position stand. Exercise and physical activity for older adults. Medicine and Science in Sports and Exercise. 2009;41(7):1510-30.

31. Get Ireland Active. 2015 [Available from: http://www.getirelandactive.ie/].

32. Get Ireland Walking. 2015 [Available from: http://www.getirelandwalking.ie/].

33. Westgarth C, Christley RM, Christian HE. How might we increase physical activity through dog walking?: A comprehensive review of dog walking correlates. The International Journal of Behavioral Nutrition and Physical Activity. 2014;11:83.

34. Beetz A, Uvnas-Moberg K, Julius H, Kotrschal K. Psychosocial and psychophysiological effects of human-animal interactions: the possible role of oxytocin. Frontiers in Psychology. 2012;3:234.

35. Goetz JL, Keltner D, Simon-Thomas E. Compassion: an evolutionary analysis and empirical review. Psychological Bulletin. 2010;136(3):351-74.

36. Motooka M, Kennedy NL, Koike H, Yokoyama T. Effect of dog-walking on autonomic nervous activity in senior citizens. The Medical Journal of Australia. 2006;184(2):60-3.

37. Enders-Slegers M-J, Hediger K. Pet Ownership and Human-Animal Interaction in an Aging Population: Rewards and Challenges. Anthrozoös. 2019;32(2):255-65. 